\title{
Prognostic value of Cox-2 and PD-LI exp
and its relationship with tumor-infiltrating lymphocytes in resected lung adenocarcinoma
}

This article was published in the following Dove Press journal: Cancer Management and Research

\author{
Katsuhiko Shimizu \\ Riki Okita \\ Shinsuke Saisho \\ Ai Maeda \\ Yuji Nojima \\ Masao Nakata
}

Department of General Thoracic Surgery, Kawasaki Medical School, Kurashiki, Okayama, Japan
Correspondence: Katsuhiko Shimizu Department of General Thoracic Surgery, Kawasaki Medical School, 577 Matsushima, Kurashiki Okayama 70I-0192, Japan

$\mathrm{Tel} / \mathrm{fax}+8 \mathrm{I} 86464$ I I 24

Email kshimizu@med.kawasaki-m.ac.jp
Abstract: Programmed cell death-1 ligand 1 (PD-L1), tumor-infiltrating CD8-positive T lymphocytes (CD8-positive TILs), and cyclooxygenase-2 (Cox-2) have been used as prognostic tools in patients with lung adenocarcinoma. We conducted a retrospective review of data from 170 patients who had undergone pulmonary resection as an initial treatment for clinical T1-2 N0 lung adenocarcinoma. We then investigated the expressions of three biomarkers using immunohistochemical analyses and compared the expression levels with the clinicopathological characteristics and outcomes of the patients. Next, we classified the tumors into four groups based on the PD-L1 and CD8-positive TILs statuses and evaluated the prognostic significance of Cox-2 expression according to the tumor immune microenvironment classification. Tumors with positive PD-L1 expression levels had a significantly larger number of CD8-positive TILs than tumors with negative PD-L1 expression levels, whereas tumors with high Cox-2 expressions had significantly fewer CD8-positive TILs than tumors with low Cox-2 expressions. A multivariate analysis showed that histological subtype, nodal metastasis, CD8-positive TILs count, and PD-L1 expression were independent predictors of patient outcome. Using a classification based on the PD-L1 and CD8-positive TILs statuses, the outcomes of patients with a negative PD-L1 expression and a high CD8-positive TIL count were significantly better than those with other classifications. In patients with negative PD-L1 and low CD8-positive TILs, the rate of EGFR mutation was significantly higher than that in other classifications, and Cox-2 expression was a powerful predictor of outcome. Clinical and pathological features in conjunction with the tumor immune microenvironment classification indicate that lung adenocarcinoma should be divided into different subgroups for prognosis and treatment. Classification according to the PD-L1 and CD8-positive TILs statuses might enable the effects of Cox-2 inhibitor to be predicted.

Keywords: non-small-cell lung cancer, tumor microenvironment, programmed cell death-1 ligand 1 (PD-L1), tumor-infiltrating CD8-positive T lymphocytes, cyclooxygenase-2 (Cox-2)

\section{Introduction}

Lung cancer is a major cause of death in many developed countries. Surgical resection is the most important curative treatment, especially for early-stage non-small-cell lung cancer (NSCLC). However, the 5-year survival rate of surgically treated NSCLC patients remains at about $70 \% ., 2$ To date, many biomarkers have now been reported as predictors of survival and recurrence in patients with NSCLC. Especially, immunological biomarkers in the tumor microenvironment are useful prognostic predictors, in addition to being promising targets for novel therapeutic approaches. ${ }^{3}$ In the present study, we investigated three biomarkers of the tumor microenvironment: programmed cell 
death-1 ligand 1 (PD-L1), tumor-infiltrating CD8-positive T lymphocytes (CD8-positive TILs), and cyclooxygenase-2 (Cox-2).

The interaction between programmed cell death-1 (PD-1) and PD-L1 inhibits T-cell activation and proliferation, leading to the immune evasion of tumor cells. ${ }^{4,5}$ Recent clinical studies using immunocheckpoint inhibitors targeting PD-1 or PD-L1 have shown promising results in patients with several types of cancer, including NSCLC. ${ }^{6-10}$ Several studies have reported that $\mathrm{PD}-\mathrm{L} 1$ expression is a predictor of a poor clinical outcome in patients with NSCLC. ${ }^{11-13}$ In addition, PD-L1 overexpression was correlated with an improved response to treatment with immunocheckpoint inhibitors. ${ }^{7-10,14}$

The importance of lymphocytic infiltration in predicting tumor progression has been shown in several types of cancer. Several reports have indicated that tumor-infiltrating $T$ cells are associated with reduced recurrence rates and longer survival periods among patients with colorectal, ovarian, or breast cancer. ${ }^{15-17}$ As a major component of the adaptive immune system, cytotoxic $\mathrm{T}$ cells are a candidate biomarker for the tumor-associated immune response. Most previous studies of CD8-positive TILs in NSCLC have reported an association with a favorable outcome. ${ }^{18-20}$

Cox is the key enzyme required for the conversion of arachidonic acid to prostaglandins. Especially, Cox-2 is an inducible enzyme that is activated in response to extracellular stimuli, such as growth factors and pro-inflammatory cytokines. ${ }^{21}$ Some investigators have demonstrated that Cox-2 is constitutively overexpressed in a variety of cancers, such as the lung, breast, pancreas, colon, esophagus, and head and neck cancers, and Cox-2 overexpression is usually associated with a poor prognosis. ${ }^{22-24}$

In the present study, we tested whether the numbers of CD8-positive TILs were correlated with PD-L1 or Cox-2 expression in primary tumors and investigated the significance of Cox-2 expression among PD-L1/CD8-positive TILs expression patterns in clinical (c) T1-2 N0 lung adenocarcinoma.

\section{Patients and methods}

\section{Patients and specimens}

A total of 170 patients who underwent pulmonary resection as an initial treatment for lung adenocarcinoma at our hospital between 2007 and 2013 were included in this study. The tumor, node, and metastasis (TNM) stage was determined according to the revised criteria published in 2009 (version 7; TNM-7). ${ }^{25}$ The histological diagnoses of the tumors were based on the criteria of the International Association for the Study of Lung Cancer/the American Thoracic Society/the European Respira- tory Society in $2011 .{ }^{26}$ All the patients included in the present analysis met the following criteria: 1) curative resection; 2) neither radiotherapy nor chemotherapy administered prior to surgery; and 3) invasive adenocarcinoma (neither in situ nor minimally invasive adenocarcinoma). Written informed consent for the study of excised tissue samples was obtained from each patient. This study was conducted with the approval of the Ethics Committee of Kawasaki Medical School (No. 2511; approved on September 30, 2016).

The mean age of patients was 68.6 years (range, 37-88 years). The duration of the follow-up period ranged from 1.1 to 90.6 months (median $=42.5$ months). Of the 170 patients, 153 , 14 , and 3 patients underwent a lobectomy, segmentectomy, and wedge resection, respectively. The histological subtype was lepidic predominant in 58 patients, acinar predominant in 53 patients, papillary predominant in 45 patients, and solid predominant in 19 patients. The TNM-7 cancer stages were IA, IB, II, and IIIA in 74, 56, 17, and 23 patients, respectively.

Selection of the postoperative adjuvant chemotherapy regimen was based on the results of a discussion among the hospital's cancer board and on enrollment in a clinical trial. In practice, oral tegafur was selected for patients with stage I disease (T1bN0M0 and T2N0M0), and platinum-based chemotherapy was selected for patients with stage II or IIIA disease.

\section{Immunohistochemical (IHC) analysis and assessment}

IHC analyses of resected, paraffin-embedded lung cancer tissues were performed. After microtome sectioning ( $4 \mu \mathrm{m})$, the slides were processed for staining using an automated immunostainer (Nexes; Ventana, Tucson, AZ, USA). The streptavidin-biotin-peroxidase detection technique using diaminobenzidine as the chromogen was applied. The primary antibodies were used according to the manufacturer's instructions. The slides were examined by two investigators who had no knowledge of the corresponding clinicopathological data. IHC was performed using the following antibodies: a mouse monoclonal anti-PD-L1 antibody (1:100, clone SP142; Spring Bioscience, Pleasanton, CA, USA), CD8 (1:50, clone C8/144B, Dako; Agilent Technologies, Inc., Santa Clara, CA, USA), and Cox-2 (1:50, clone CX-294, Dako; Agilent Technologies, Inc.) according to a previously described protocol. ${ }^{8,18,27}$

The expression levels of each marker protein were examined and evaluated according to a previously reported original protocol. PD-L1 expression was categorized as positive when staining of the tumor cell membrane (at any intensity) was present. PD-L1 positive expression was observed at prespecified expression levels of $5 \%$ of all cells in a section that included 
at least 100 evaluable tumor cells. ${ }^{8}$ In order to evaluate the immunostaining of the CD8-positive TILs, 10 digital highpower field (HPF) images of the tumor area were selected, and the absolute number of CD8-positive TILs in these images was determined. ${ }^{18}$ For Cox-2, the slides were scored according to the intensity of staining $(0-3)$ and the percentage of positively stained cells $(0,0 \% ; 1,1 \%-9 \% ; 2,10 \%-49 \%$; and $3,50 \%-100 \%)$. The IHC score (0-9) was calculated by multiplying the intensity and percentage scores. Cox- 2 expression was considered high when the IHC score was $\geq 4 .{ }^{27}$ Figure 1 depicts the IHC Cox-2 expression levels in the tissues.

\section{Tumor immune microenvironment classification}

The classification of tumors into four groups based on the PD-L1 and CD8-positive TILs statuses has been previously proposed. ${ }^{28}$ These classifications were type I (PD-L1 positive with CD8-positive TILs driving adaptive immune resistance), type II (PD-L1 negative with no CD8-positive TILs indicating immune ignorance), type III (PD-L1 positive with no CD8-positive TILs indicating intrinsic induction), and type IV (PD-L1 negative with CD8-positive TILs indicating the role of other suppressors in promoting immune tolerance). Figure 2 depicts the IHC PD-L1 and CD8-positive TILs expression patterns in the tissues.

\section{EGFR mutation analysis}

An analysis to detect EGFR mutations was performed using resected, paraffin-embedded lung cancer tissues and the peptide nucleic acid-locked nucleic acid (PNA-LNA) PCR clamp method. ${ }^{29}$ The PNA-LNA PCR clamp assay was performed at Mitsubishi Kagaku Bio-Clinical Laboratories, Inc.

\section{Statistical analysis}

All the statistical analyses were performed by using the SPSS statistical package (Version 17.0; SPSS, Chicago, IL, USA). Categorical data were examined by using the $\chi^{2}$ test. The prognostic evaluation was performed based on recurrence-free

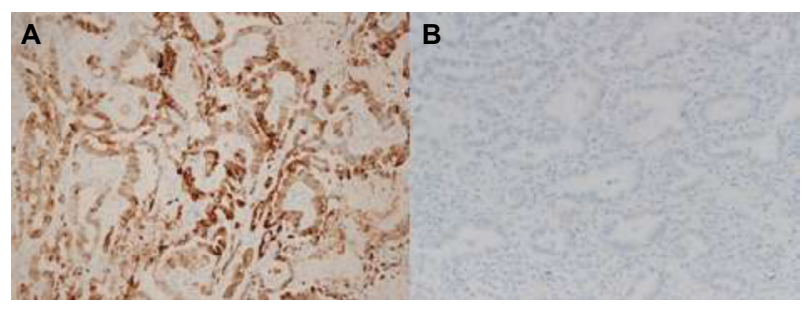

Figure I Representative sections of lung adenocarcinoma tissues with cytoplasmic staining for Cox-2. (A) High expression; (B) low expression. Abbreviation: Cox-2, cyclooxygenase-2. survival (RFS). RFS was defined as the time from the date of surgery until lung cancer recurrence or non-lung cancer death. The survival curves were estimated using the Kaplan-Meier method, and differences were evaluated using the log rank test. Univariate and multivariate analyses were performed using the Cox proportional hazards model. Two-sided $P$-values of $<0.05$ were considered statistically significant.

\section{Results \\ CD8-positive TILs counts according to PD-LI and Cox-2 expression}

The minimum and maximum numbers of CD8-positive TILs per HPF were 5 and 276, respectively. There were 59 patients

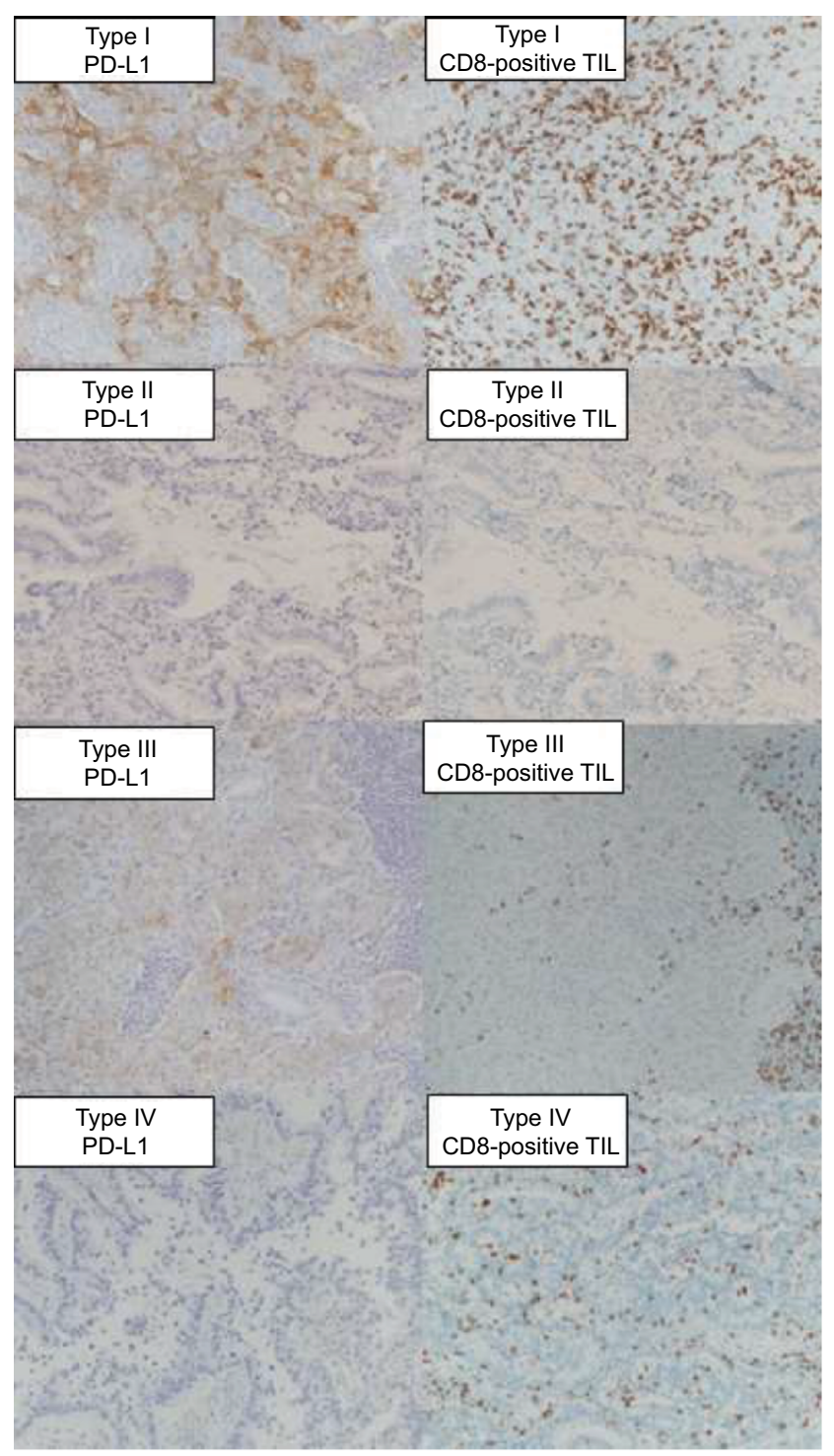

Figure 2 Representative sections of lung adenocarcinoma tissues with CD8positive TILs and cell membrane staining for PD-LI according to tumor immune microenvironment classification.

Abbreviations: CD8-positive TILs, tumor-infiltrating CD8-positive T lymphocytes: PD-LI, programmed cell death-I ligand I. 
with positive PD-L1 expression tumors and 111 patients with negative PD-L1 expression tumors. There were 78 patients with high Cox-2 expression tumors and 92 patients with low Cox-2 expression tumors.

The positive PD-L1 expression tumors showed a significantly larger number of CD8-positive TILs than the negative PD-L1 tumors $(P=0.010$; Figure 3A). In contrast, the high Cox-2 expression tumors showed significantly fewer CD8positive TILs than the low Cox- 2 tumors $(P=0.020$; Figure $3 B)$. In addition, the mean number of CD8-positive TILs was lower for $E G F R$ mutant type than for $E G F R$ wild type $(P=0.040)$. There was no difference between the CD8-positive TILs and smoking status $(P=0.124)$ or the blood lymphocyte count $(P=0.575$; Table 1$)$.

\section{Relationship between PD-LI and Cox-2 expression levels and clinicopathological factors}

As for the relationships between the PD-L1 expression level and the clinicopathological factors, patients with positive PD-L1 expression tumors had a significantly higher percentage of male gender, smokers, nonlepidic subtype, and a negative EGFR mutation status than those with negative PD-L1 expression tumors. In contrast, patients with high Cox-2 expression tumors had a significantly higher percentage of male genders, smoker, nonlepidic subtype, and lymph node metastasis than those with low Cox-2 expression tumors (Table 2).

A

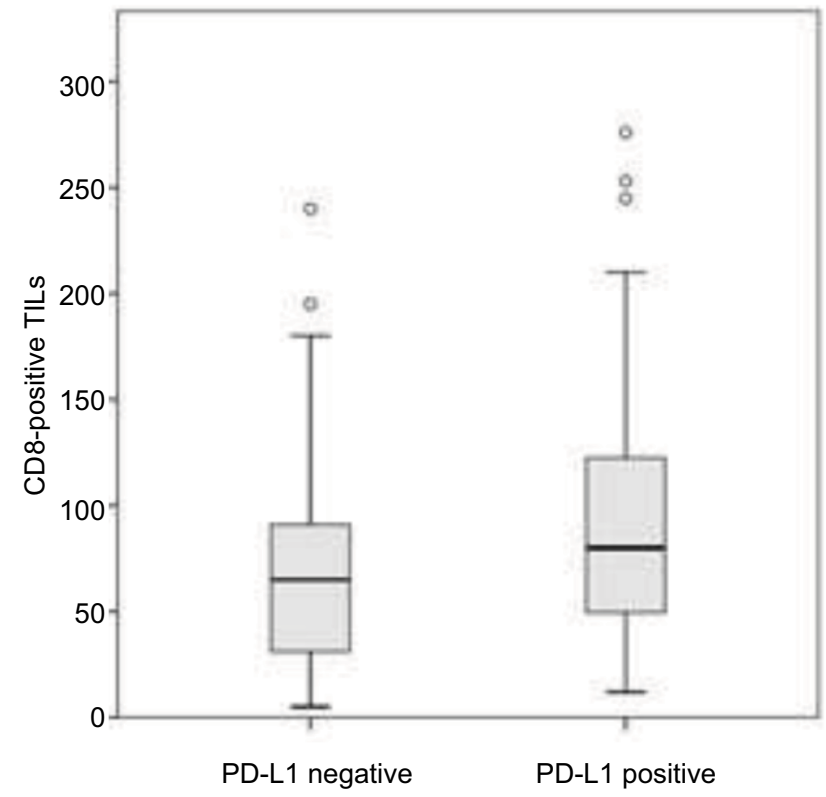

Relationship between tumor immune microenvironment and clinicopathological factors

The tumor immune microenvironment classifications were type I (high PD-L1 and high CD8-positive TILs), type II (low PD-L1 and low CD8-positive TILs), type III (high PD-L1 and low CD8-positive TILs), and type IV (low PD-L1 and high CD8-positive TILs) in 30, 71, 29, and 40 patients, respectively. Table 3 shows the relationships between the

Table I Relationship between CD8-positive TILs count and biomarkers

\begin{tabular}{llll}
\hline Variable & & $\begin{array}{l}\text { CD8-positive } \\
\text { TILs count }\end{array}$ & P-value \\
\hline $\begin{array}{l}\text { PD-LI } \\
\quad \text { Negative }\end{array}$ & 111 & $69.66 \pm 47.91$ & 0.010 \\
$\quad$ Positive & 59 & $93.75 \pm 60.95$ & \\
Cox-2 & & & 0.020 \\
Low & 92 & $86.78 \pm 54.74$ & \\
High & 78 & $67.68 \pm 51.25$ & \\
EGFR mutation & & & 0.040 \\
$\quad$ Negative & 50 & $83.80 \pm 49.25$ & \\
$\quad$ Positive & 43 & $62.84 \pm 47.41$ & 0.124 \\
Smoking status & & & \\
$\quad$ Never & 90 & $71.97 \pm 49.83$ & 0.575 \\
$\quad$ Smoker & 80 & $84.83 \pm 57.63$ & \\
Lymphocyte count & & & \\
$\quad<1900$ & 86 & $75.72 \pm 54.75$ & \\
$\quad>1900$ & 84 & $80.37 \pm 53.17$ & \\
\hline
\end{tabular}

Abbreviations: CD8-positive TILs, tumor-infiltrating CD8-positive T lymphocytes; Cox-2, cyclooxygenase-2; PD-LI, programmed cell death-I ligand I.

B

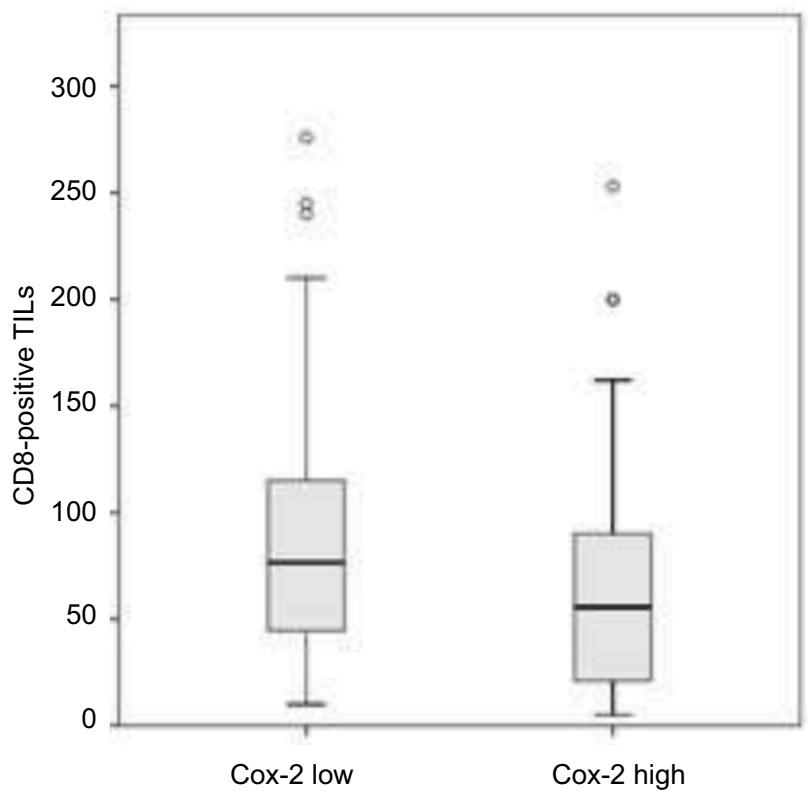

Figure 3 The numbers of CD8-positive TILs within cancer cell nest were significantly lower in cases with low-PD-LI expression (A; $P=0.010)$ and high-Cox-2 expression (B; $P=0.020$ ). Differences were tested using the Mann-Whitney $U$-test.

Abbreviations: CD8-positive TILs, tumor-infiltrating CD8-positive T lymphocytes; Cox-2, cyclooxygenase-2; PD-LI, programmed cell death-I ligand I. 
Table 2 Relationship of PD-LI and Cox-2 expression and clinicopathological factors

\begin{tabular}{|c|c|c|c|c|c|c|}
\hline \multirow[t]{2}{*}{ Variable } & \multicolumn{3}{|c|}{ PD-LI expression } & \multicolumn{3}{|c|}{ Cox-2 expression } \\
\hline & Negative & Positive & $P$-value & Low & High & P-value \\
\hline Number & 111 & 59 & & 92 & 78 & \\
\hline Age & & & 0.913 & & & 0.878 \\
\hline$\geq 70$ & 48 & 25 & & 40 & 33 & \\
\hline$<70$ & 63 & 34 & & 52 & 45 & \\
\hline Sex & & & $<0.001$ & & & 0.006 \\
\hline Male & 39 & 42 & & 35 & 46 & \\
\hline Female & 72 & 17 & & 57 & 32 & \\
\hline Smoking history & & & $<0.001$ & & & 0.007 \\
\hline Smoker & 36 & 41 & & 33 & 44 & \\
\hline Never smoker & 75 & 18 & & 59 & 34 & \\
\hline Clinical T category (TNM-7) & & & 0.631 & & & 0.174 \\
\hline TI & 81 & 41 & & 70 & 52 & \\
\hline $\mathrm{T} 2$ & 30 & 18 & & 22 & 26 & \\
\hline Histological subtype & & & 0.001 & & & 0.026 \\
\hline Lepidic & 47 & 11 & & 38 & 20 & \\
\hline Acinar & 34 & 19 & & 28 & 25 & \\
\hline Papillary & 26 & 19 & & 23 & 22 & \\
\hline Solid & 4 & 10 & & 3 & II & \\
\hline Pathological nodal status & & & 0.108 & & & 0.036 \\
\hline No & 94 & 44 & & 80 & 58 & \\
\hline $\mathrm{NI}+2$ & 17 & 15 & & 12 & 20 & \\
\hline Pathological stage (TNM-7) & & & 0.267 & & & 0.121 \\
\hline IA & 54 & 20 & & 48 & 26 & \\
\hline IB & 36 & 20 & & 28 & 28 & \\
\hline$\|A+\| B$ & 9 & 8 & & 6 & 11 & \\
\hline IIIA & 12 & 11 & & 10 & 13 & \\
\hline EGFR mutation status & & & 0.001 & & & 0.856 \\
\hline Positive & 35 & 8 & & 21 & 22 & \\
\hline Negative & 23 & 26 & & 23 & 26 & \\
\hline Unknown & 53 & 25 & & 48 & 30 & \\
\hline
\end{tabular}

Abbreviations: Cox-2, cyclooxygenase-2; PD-LI, programmed cell death-I ligand I; TNM, tumor, node, and metastasis.

tumor immune microenvironment and clinicopathological factors. Especially, patients with type II tumors had a significantly higher percentage of female gender, nonsmokers, lepidic subtype, and positive EGFR mutation status than those with other tumor types.

\section{Prognostic analysis according to PD-LI and CD8-positive TILs statuses}

The outcomes of patients with tumors exhibiting high CD8-positive TILs expression were significantly better than those of patients with low CD8-positive TILs expression ( $P=0.038$; Figure 4A). On the other hand, the outcomes of patients with tumors exhibiting positive PD-L1 expression were significantly poorer than those of patients with negative PD-L1 expression ( $P=0.005$; Figure 4B). The outcomes of patients with type IV tumors were significantly better than those of patients with type III tumors ( $P=0.002$; Figure 4C).
Impact of tumor Cox-2 expression level on the outcomes of patients according to tumor immune microenvironment classification

Among the patients with type II tumors, those with a high Cox-2 expression level had a significantly poorer outcome than those with a low Cox-2 expression level $(P=0.021$; Figure 5B). On the other hand, in patients with type I, III, or IV tumors, no significant difference in the outcome was observed between patients with high and low Cox-2 expression levels (Figure 5A, C, and D).

\section{Multivariate analysis of prognosis}

A univariate analysis identified the histological subtype of adenocarcinoma, nodal metastasis, Cox-2 expression, PD-L1 expression, and CD8-positive TILs status as predictors of RFS. On the other hand, a multivariate analysis using a Cox 
Table 3 Relationship of tumor immune microenvironment and clinicopathological factors

\begin{tabular}{|c|c|c|c|c|c|}
\hline Variable & Type I & Type II & Type III & Type IV & $P$-value \\
\hline Number & 30 & 71 & 29 & 40 & \\
\hline Age & & & & & 0.645 \\
\hline$\geq 70$ & 11 & 33 & 14 & 15 & \\
\hline$<70$ & 19 & 38 & 15 & 25 & \\
\hline Sex & & & & & 0.001 \\
\hline Male & 23 & 21 & 19 & 18 & \\
\hline Female & 7 & 50 & 10 & 22 & \\
\hline Smoking history & & & & & $<0.001$ \\
\hline Smoker & 24 & 21 & 19 & 16 & \\
\hline Never & 6 & 50 & 10 & 24 & \\
\hline Clinical T category (TNM-7) & & & & & 0.924 \\
\hline TI & 22 & 54 & 19 & 27 & \\
\hline $\mathrm{T} 2$ & 8 & 17 & 10 & 13 & \\
\hline Histological subtype & & & & & 0.027 \\
\hline Lepidic & 6 & 33 & 5 & 14 & \\
\hline Acinar & 9 & 19 & 10 & 15 & \\
\hline Papillary & 9 & 16 & 10 & 10 & \\
\hline Solid & 6 & 3 & 4 & 1 & \\
\hline Pathological Nodal status & & & & & 0.253 \\
\hline No & 24 & 59 & 20 & 35 & \\
\hline $\mathrm{NI}+2$ & 6 & 12 & 9 & 5 & \\
\hline Pathological stage (TNM-7) & & & & & 0.016 \\
\hline IA & 12 & 37 & 8 & 17 & \\
\hline IB & 11 & 20 & 9 & 16 & \\
\hline$\|A+\| B$ & 4 & 4 & 4 & 5 & \\
\hline IIIA & 3 & 10 & 8 & 2 & \\
\hline EGFR mutation status & & & & & 0.001 \\
\hline Positive & 4 & 27 & 4 & 8 & \\
\hline Negative & 13 & 9 & 13 & 14 & \\
\hline Unknown & 13 & 35 & 12 & 18 & \\
\hline
\end{tabular}

Note: Type I (PD-LI positive with TILs driving), type II (PD-LI negative with no TIL), type III (PD-LI positive with no TIL), and type IV (PD-LI negative with TILs driving). Abbreviations: PD-LI, programmed cell death-I ligand I; TILs, tumor-infiltrating T lymphocytes; TNM, tumor, node, and metastasis.

proportional hazard model identified the histological subtype of adenocarcinoma $(P=0.007)$, nodal metastasis $(P<0.001)$, PD-L1 expression $(P=0.037)$, and the CD8-positive TILs status $(P=0.012)$ as independent predictors of RFS (Table 4$)$.

\section{Discussion}

We undertook this study to classify lung adenocarcinoma into four groups based on the PD-L1 expression and CD8-positive TILs statuses, and we evaluated the prognostic significance of Cox-2 expression according to the tumor immune microenvironment classification.

In a recent IHC study of NSCLC, PD-L1 expression was positively associated with current smoking status and with the presence of $K R A S$ mutations, whereas it was inversely associated with adenocarcinoma histology and the presence of EGFR mutations. ${ }^{30}$ Our study also demonstrated that PD-L1 expression was associated with the smoking status, nonlepidic adenocarcinoma subtype, and the presence of EGFR mutations.
In this study, we used the number of CD8-positive TILs as a marker of antitumor immunity, since CD8-positive TILs play a central role in the elimination of tumor cells. In fact, increased levels of CD3+ and CD8-positive TILs were associated with a better prognosis in a large study examining NSCLC. ${ }^{31}$ Furthermore, Kondratiev et al reported increased numbers of CD8-positive TILs at the invasive border of tumors as an independent factor affecting the prognosis of patients with endometrial carcinoma. ${ }^{32}$ Our study also demonstrated that an increased number of CD8-positive TILs was an independent factor correlated with the outcomes of patients with resected lung carcinoma.

In 2010, we demonstrated that the tumor-infiltrating regulatory $\mathrm{T}$ cells (Treg) count was positively correlated with intratumoral Cox-2 expression and was also associated with RFS, particularly in patients with lymph node-negative NSCLC. ${ }^{33}$ In the present study, we demonstrated that the CD8-positive TILs count was inversely correlated with intratumoral Cox-2 expression and was also associated 

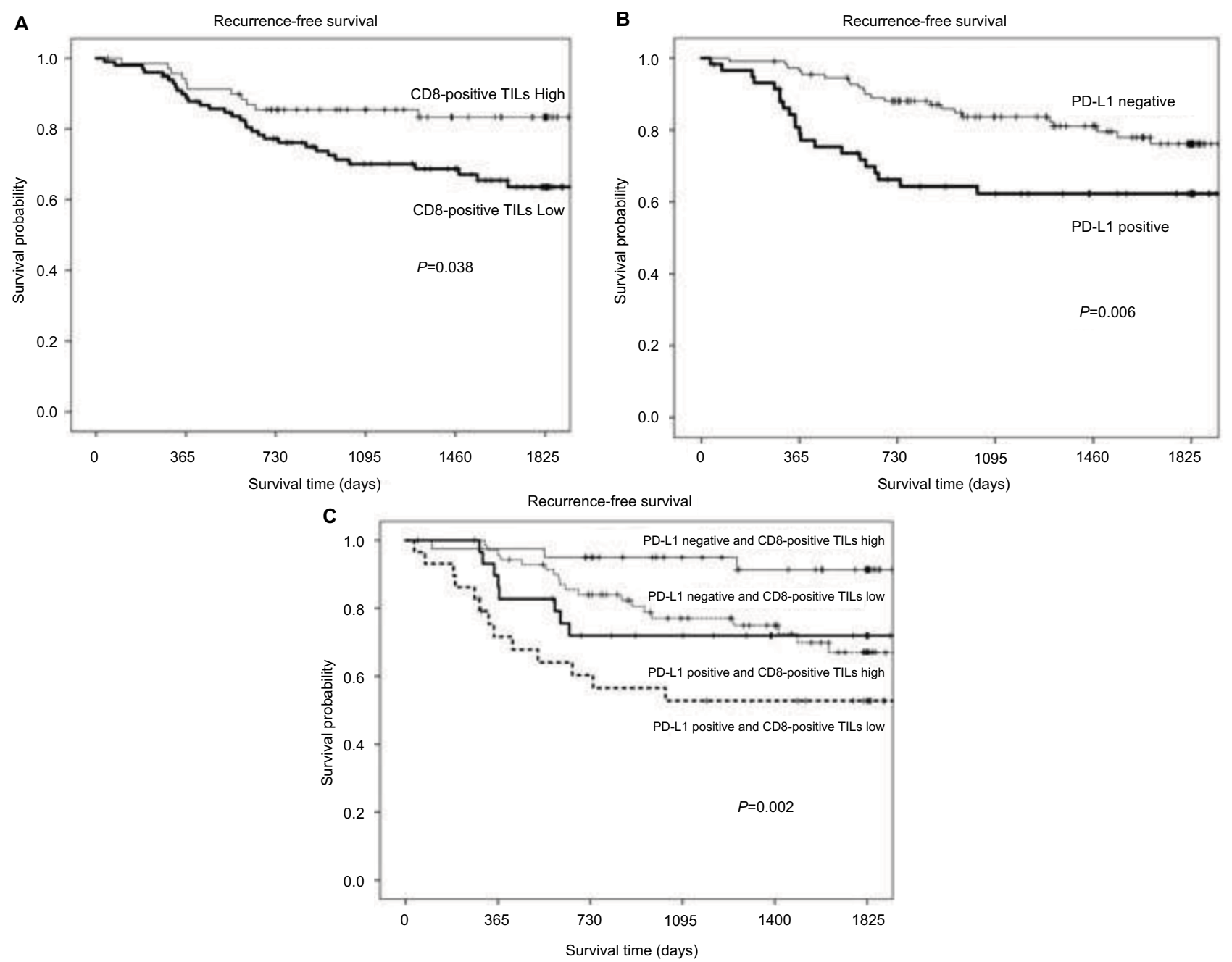

Figure 4 Comparison of recurrence-free survival rates between patients with high CD8-positive TILs counts versus those with low CD8-positive TILs counts (A), high PD$\mathrm{LI}$ expressions versus low PD-LI expressions (B), and tumor microenvironment type IV versus type I versus type II versus type III (C). $P=0.038,0.006$, and 0.002 , respectively. Abbreviations: CD8-positive TILs, tumor-infiltrating CD8-positive T lymphocytes; PD-LI, programmed cell death-I ligand I.

with the RFS in patients with lymph node-negative lung adenocarcinoma. Based on these studies, Cox-2 appears to function exactly opposite to CD8-positive TILs and Treg. Cox-2 expression is positively correlated $(P<0.001)$ with the Tregs count, whereas it is inversely correlated with the CD8-positive TILs count ( $P=0.020)$.

In addition, to the best of our knowledge, the current study was the first to use Cox-2 expression to assess PDL1 and CD8-positive TILs subtypes. In endometrial cancer, Ohno et al reported that a decrease in the number of CD8positive TILs was associated with a good prognosis and that Cox-2 expression tended to be associated with a decrease in the number of CD8-positive TILs. ${ }^{34}$ Recently, Botti et al described a potential relationship between Cox-2 and PD-L1 expression in melanoma. ${ }^{35} \mathrm{Cox}-2$ expression was correlated with and modulates PD-L1 expression in melanoma cells. These findings have clinical relevance, since they provide a rationale to implement novel clinical trials to test Cox-2 inhibition as a potential treatment to prevent cancer progression and immune evasion.

\section{Limitations}

This study had several limitations that should be considered when interpreting the results. The retrospective study design and the relatively small number of enrolled patients were the major limitations of the present study. Second, we used SP142 for the PD-L1 antibody; in the Blueprint PD-L1 IHC Assay Comparison Project, however, an analytical comparison demonstrated that the percentage of PD-L1-stained tumor cells was comparable when the $22 \mathrm{C} 3,28-8$, and SP263 assays were used, whereas the SP142 assay exhibited fewer stained tumor cells overall. ${ }^{36}$

\section{Conclusion}

Our IHC findings suggested that CD8-positive TILs are correlated with PD-L1 or Cox-2 expression among cT1-2 

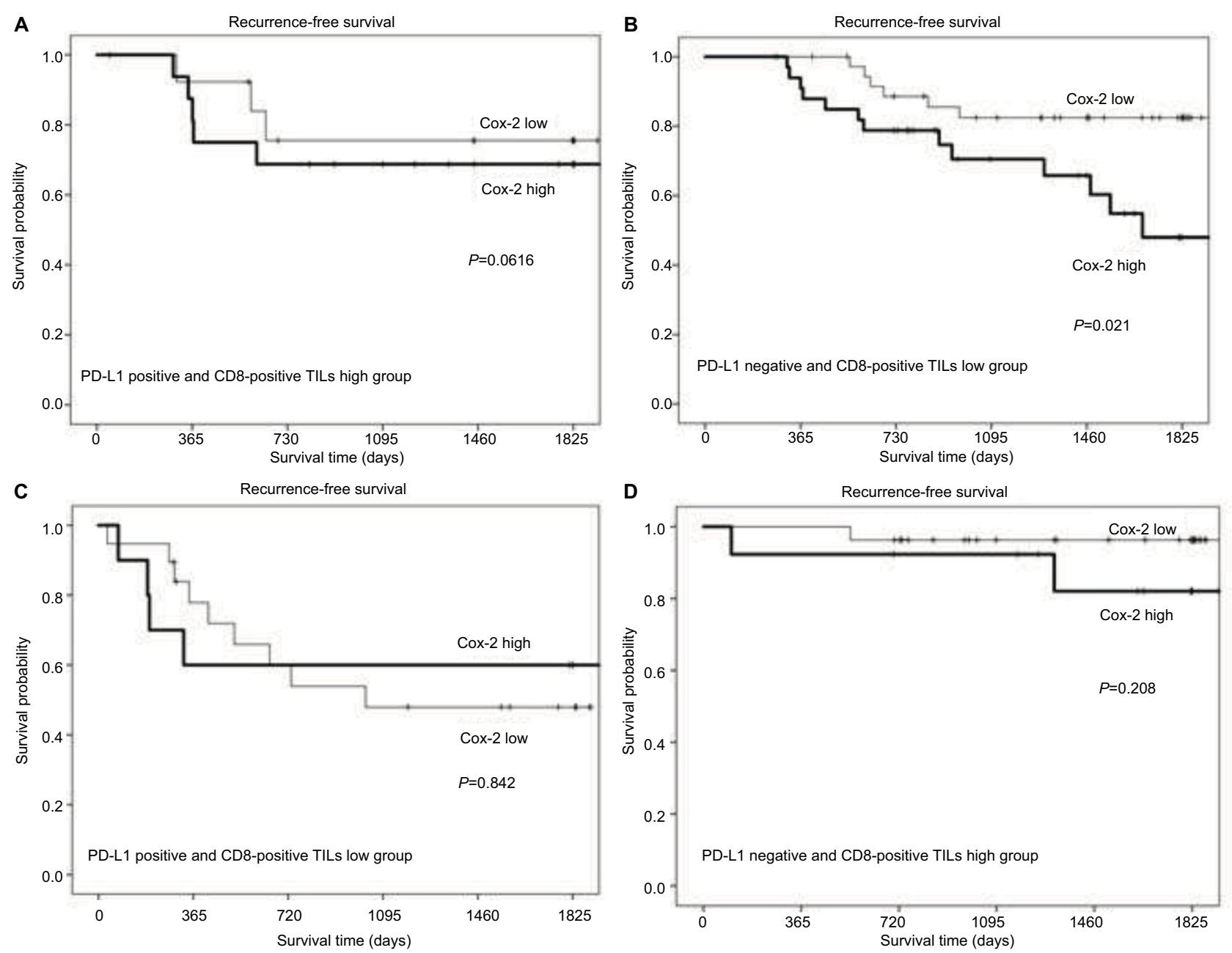

Figure 5 Comparisons of recurrence-free survival rates between patients with high Cox-2 expression versus low Cox-2 expression, according to tumor microenvironment status: type I (A), type II (B), type III (C), and type IV (D). P=0.616, 0.021, 0.842, and 0.208, respectively.

Abbreviations: CD8-positive TILs, tumor-infiltrating CD8-positive T lymphocytes; Cox-2, cyclooxygenase-2; PD-LI, programmed cell death-I ligand I.

Table 4 Results of the univariate and multivariate cox regression analyses of recurrence-free survival

\begin{tabular}{|c|c|c|c|c|c|c|}
\hline \multirow[t]{2}{*}{ Variable } & \multicolumn{3}{|c|}{ Univariate } & \multicolumn{3}{|c|}{ Multivariate } \\
\hline & HR & $95 \% \mathrm{Cl}$ & $P$-value & HR & $95 \% \mathrm{Cl}$ & $P$-value \\
\hline \multicolumn{7}{|l|}{ Sex } \\
\hline Male/female & 1.51 & $0.83-2.750 .176$ & & & & \\
\hline \multicolumn{7}{|l|}{ Age } \\
\hline$\geq 70 /<70$ & 1.28 & $0.7 I-2.32$ & $0.41 I$ & & & \\
\hline \multicolumn{7}{|l|}{ Histological subtype } \\
\hline Nonlepidic/lepidic & 6.49 & $2.32-18.17$ & $<0.001$ & 4.33 & $|.5|-\mid 2.5$ & 0.007 \\
\hline \multicolumn{7}{|c|}{ Pathological T (TNM-7) } \\
\hline $\mathrm{T} 2 / \mathrm{TI}$ & 1.72 & $0.93-3.16$ & 0.084 & & & \\
\hline \multicolumn{7}{|l|}{ Pathological $\mathrm{N}$ factor } \\
\hline Positive/negative & 8.58 & $4.67-15.78$ & $<0.001$ & 6.36 & $3.37-11.99$ & $<0.001$ \\
\hline \multicolumn{7}{|l|}{ Cox-2 expression } \\
\hline High/low & 2.05 & $1.11-3.76$ & 0.021 & 1.10 & $0.58-2.10$ & 0.773 \\
\hline \multicolumn{7}{|l|}{ PD-LI expression } \\
\hline Positive/negative & 2.30 & $1.27-4.16$ & 0.006 & 1.96 & $1.04-3.69$ & 0.037 \\
\hline \multicolumn{7}{|c|}{ CD8-positive TILs count } \\
\hline High/low & 0.50 & $0.26-0.96$ & 0.038 & 0.41 & $0.21-0.82$ & 0.012 \\
\hline
\end{tabular}

Abbreviations: Cox-2, cyclooxygenase-2; PD-LI, programmed cell death-I ligand I; TILs, tumor-infiltrating T lymphocytes; TNM, tumor, node, and metastasis. 
N0 lung adenocarcinoma patients. Based on a classification according to PD-L1 expression and CD8-positive TILs statuses, the outcomes of patients with low PD-L1 expressions and high CD8-positive TILs counts were significantly better than those of patients with high PD-L1 expressions and low CD8-positive TILs counts. Cox-2 expression was a powerful predictor of RFS, especially in patients with low PD-L1 expressions and low CD8-positive TILs counts. Clinical and pathological features, in conjunction with the tumor immune microenvironment classification, indicated that lung adenocarcinoma should be divided into different subgroups for prognosis and treatment. Classification according to the PD-L1 and CD8-positive TILs statuses might enable the effects of Cox-2 inhibitor to be predicted.

\section{Acknowledgments}

The authors thank Keiko Isoda for providing technical assistance, and they would like to thank International Medical Information Center (http://www.imic.or.jp/) for the English language review.

\section{Disclosure}

The authors report no conflicts of interest in this work.

\section{References}

1. Asamura H, Goya T, Koshiishi Y, et al. A Japanese Lung Cancer Registry Study: prognosis of 13,010 resected lung cancers. J Thorac Oncol. 2008;3:46-52.

2. Sawabata N, Miyaoka E, Asamura H, et al. Japanese lung cancer registry study of 11,663 surgical cases in 2004: demographic and prognosis changes over decade. J Thorac Oncol. 2011;6:1229-1235.

3. Shimizu K, Okita R, Nakata M. Clinical significance of the tumor microenvironment in non-small cell lung cancer. Ann Transl Med. 2013;1:20.

4. Freeman GJ, Long AJ, Iwai Y, et al. Engagement of the PD-1 immunoinhibitory receptor by a novel B7 family member leads to negative regulation of lymphocyte activation. J Exp Med. 2000;192:1027-1034.

5. Blank C, Gajewski TF, Mackensen A. Interaction of PD-L1 on tumor cells with PD-1 on tumor-specific T cells as a mechanism of immune evasion: implications for tumor immunotherapy. Cancer Immunol Immunother. 2005;54:307-314.

6. Weber JS, D'Angelo SP, Minor D, et al. Nivolumab versus chemotherapy in patients with advanced melanoma who progressed after anti-CTLA-4 treatment (CheckMate 037): a randomised, controlled, open-label, phase 3 trial. Lancet Oncol. 2015;16:375-384.

7. Brahmer J, Reckamp KL, Baas P, et al. Nivolumab versus docetaxel in advanced squamous-cell non-small-cell lung cancer. $N$ Engl $\mathrm{J} \mathrm{Med}$. 2015;373:123-135.

8. Borghaei H, Paz-Ares L, Horn L, et al. Nivolumab versus docetaxel in advanced nonsquamous non-small-cell lung cancer. $N$ Engl $\mathrm{J}$ Med. 2015;373:1627-1639.

9. Herbst RS, Baas P, Kim DW, et al. Pembrolizumab versus docetaxel for previously treated, PD-L1-positive, advanced non-small-cell lung cancer (KEYNOTE-010): a randomised controlled trial. Lancet. 2016;387:1540-1550.

10. Reck M, Rodríguez-Abreu D, Robinson AG, et al. Pembrolizumab versus chemotherapy for PD-L1-positive non-small-cell lung cancer. N Engl J Med. 2016;375:1823-1833.
11. Velcheti V, Schalper KA, Carvajal DE, et al. Programmed death ligand-1 expression in non-small cell lung cancer. Lab Invest. 2014;94:107-116.

12. Shimoji M, Shimizu S, Sato K, et al. Clinical and pathologic features of lung cancer expressing programmed cell death ligand 1 (PD-L1). Lung Cancer. 2016;98:69-75.

13. Sun JM, Zhou W, Choi YL, et al. Prognostic significance of PD-L1 in patients with non-small cell lung cancer: a large cohort study of surgically resected cases. J Thorac Oncol. 2016;11:1003-1011.

14. Yang CY, Lin MW, Chang YL, Wu CT, Yang PC. Programmed cell death-ligand 1 expression in surgically resected stage I pulmonary adenocarcinoma and its correlation with driver mutations and clinical outcomes. Eur J Cancer. 2014;50:1361-1369.

15. Galon J, Costes A, Sanchez-Cabo F, et al. Type, density, and location of immune cells within human colorectal tumors predict clinical outcome. Science. 2006;313:1960-1964.

16. Zhang L, Conejo-Garcia JR, Katsaros D, et al. Intratumoral T cells, recurrence, and survival in epithelial ovarian cancer. $N$ Engl $J$ Med. 2003;348:203-213.

17. Ali HR, Provenzano E, Dawson SJ, et al. Association between CD8+ T-cell infiltration and breast cancer survival in 12,439 patients. Ann Oncol. 2014;25:1536-1543.

18. Kinoshita T, Muramatsu R, Fujita T, et al. Prognostic value of tumorinfiltrating lymphocytes differs depending on histological type and smoking habit in completely resected non-small-cell lung cancer. Ann Oncol. 2016;27:2117-2123.

19. Teng F, Meng X, Wang X, et al. Expressions of CD8+TILs, PD-L1 and Foxp3+TILs in stage I NSCLC guiding adjuvant chemotherapy decisions. Oncotarget. 2016;7:64318-64329.

20. Donnem T, Hald SM, Paulsen EE, et al. Stromal CD8+ T-cell density-a promising supplement to TNM staging in non-small cell lung cancer. Clin Cancer Res. 2015;21:2635-2643.

21. Dubois RN, Abramson SB, Crofford L, et al. Cyclooxygenase in biology and disease. FASEB J. 1998;12:1063-1073.

22. Hida T, Yatabe Y, Achiwa H, et al. Increased expression of cyclooxygenase 2 occurs frequently in human lung cancers, specifically in adenocarcinomas. Cancer Res. 1998;58:3761-3764.

23. Hwang D, Scollard D, Byrne J, Levine E. Expression cyclooxygenase-1 and cyclooxygenase-2 in human breast cancer. $J$ Natl Cancer Inst. 1998;90:455-460.

24. Ogino S, Kirkner GJ, Nosho K, et al. Cyclooxygenase-2 expression is an independent predictor of poor prognosis in colon cancer. Clin Cancer Res. 2008;14:8221-8227.

25. Goldstraw P, Crowley J, Chansky K, et al. The IASLC Lung Cancer Staging Project: proposals for the revision of the TNM stage groupings in the forthcoming (seventh) edition of the TNM Classification of malignant tumours. J Thorac Oncol. 2007;2:706-714.

26. Travis WD, Brambilla E, Noguchi M, et al. International Association for the Study of Lung Cancer/American Thoracic Society/European Respiratory Society: international multidisciplinary classification of lung adenocarcinoma. J Thorac Oncol. 2011;6:244-285.

27. Edelman MJ, Watson D, Wang X, et al. Eicosanoid modulation in advanced lung cancer: cyclooxygenase- 2 expression is a positive predictive factor for celecoxib + chemotherapy - Cancer and Leukemia Group B Trial 30203. J Clin Oncol. 2008;26:848-855.

28. Teng MW, Ngiow SF, Ribas A, Smyth MJ. Classifying cancers based on T cell infiltration and PD-L1. Cancer Res. 2015;75:2139-2145.

29. Nagai Y, Miyazawa H, Huqun, et al. Genetic heterogeneity of the epidermal growth factor receptor in non-small cell lung cancer cell lines revealed by a rapid and sensitive detection system, the peptide nucleic acid-locked nucleic acid PCR clamp. Cancer Res. 2005;65: 7276-7282.

30. D'Incecco A, Andreozzi M, Ludovini V, et al. PD-1 and PD-L1 expression in molecularly selected non-small-cell lung cancer patients. $B r J$ Cancer. 2015;112:95-102.

31. Schalper KA, Brown J, Carvajal-Hausdorf D, et al. Objective measurement and clinical significance of TILs in non-small cell lung cancer. J Natl Cancer Inst. 2015;107:pii: dju435. 
32. Kondratiev S, Sabo E, Yakievich E, Lavie O, Resnick MB. Intratumoral $\mathrm{CD} 8+\mathrm{T}$ lymphocytes as a prognostic factor of survival in endometrial carcinoma. Clin Cancer Res. 2004;10:4450-4456.

33. Shimizu K, Nakata M, Hirami Y, Yukawa K, Maeda A, Tanemoto K. Tumor-infiltrating Foxp3+ regulatory t cells are correlated with cyclooxygenese-2 expression and are associated with recurrence in resected non-small cell lung cancer. J Thorac Oncol. 2010;5:585-590.

34. Ohno Y, Ohno S, Suzuki N, et al. Role of cyclooxygenase-2 in immunomodulation and prognosis of endometrial carcinoma. Int J Cancer. 2005;114:696-701.
35. Botti G, Fratangelo F, Cerrone M, et al. COX-2 expression positively correlates with PD-L1 expression in human melanoma cells.JTransl Med.2017; $15: 46$

36. Hirsch FR, McElhinny A, Stanforth D, et al. PD-L1 immunohistochemistry assays for lung cancer: results from phase 1 of the BLUEPRINT PD-L1 IHC Assay Comparison Project. J Thorac Oncol. 2017;12: 208-222.

\section{Publish your work in this journal}

Cancer Management and Research is an international, peer-reviewed open access journal focusing on cancer research and the optimal use of preventative and integrated treatment interventions to achieve improved outcomes, enhanced survival and quality of life for the cancer patient. The manuscript management system is completely online and includes a very quick and fair peer-review system, which is all easy to use. Visit http://www.dovepress.com/testimonials.php to read real quotes from published authors. 